\title{
Prevalência de neoplasias diagnosticadas em cães no Hospital Veterinário da Universidade Eduardo Mondlane, Moçambique
}

\author{
[Prevalence of neoplasia diagnosed in dogs at the Veterinary Hospital at Eduardo Mondlane \\ University, Mozambique] \\ I.F.C. Santos ${ }^{1,5}$, J.M.M. Cardoso ${ }^{1}$, K.C. Oliveira ${ }^{3}$, C.J.M. Laisse ${ }^{2}$, S.A.T. Bessa ${ }^{4}$ \\ ${ }^{1}$ Faculdade de Veterinária - Universidade Eduardo Mondlane - Maputo, Moçambique \\ ${ }^{2}$ Faculdade de Veterinária - Universidade Eduardo Mondlane- Maputo, Moçambique \\ ${ }^{3}$ Médica veterinária autônoma - Taboão da Serra, SP \\ ${ }^{4}$ Médica veterinária autônoma - Maputo, Moçambique \\ ${ }^{5}$ Aluno de pós-graduação - UNESP - Botucatu, SP
}

\begin{abstract}
RESUMO
Realizou-se um estudo retrospectivo em 210 cães acometidos por neoplasias, atendidos no Hospital Veterinário (HV) da Universidade Eduardo Mondlane, Moçambique, no período de janeiro de 2004 a janeiro de 2009. Foram utilizados dados das fichas clínico-cirúrgicas, referentes às amostras de neoplasias removidas cirurgicamente, achados de exames necroscópicos e citológicos, os quais, posteriormente, foram enviados para o diagnóstico histopatológico. As neoplasias foram correlacionadas com o sexo, a idade e a raça. Foram identificadas 210 neoplasias durante o período de estudo, e dos 27 tipos diferentes as que se destacaram foram as de pele $(61,0 \%)$, seguidas das neoplasias de glândula mamária $(27,60 \%)$, do sistema reprodutor $(11,90 \%)$ e do sistema musculoesquelético $(11,0 \%)$. As neoplasias de glândula mamária foram identificadas somente em cadelas, observando-se maior prevalência em cadelas não castradas ou castradas após os dois anos de idade. Concluiu-se que o aumento da prevalência das neoplasias estava correlacionado com a maior longevidade dos cães, e a raça, também, predispôs ao desenvolvimento de determinados tumores, haja vista a alta incidência de mastocitomas grau II em cães das raças Boxer e Pastor Alemão. A incidência de 100\% das neoplasias de glândula mamária em fêmeas confirmou a maior predisposição das fêmeas no desenvolvimento desse tipo de neoplasia.
\end{abstract}

Palavras-chave: cão, neoplasias, histopatologia, Moçambique

\begin{abstract}
A retrospective study of tumors in dogs was carried out in the School Veterinary Hospital (HVE), Eduardo Mondlane University, Mozambique, between January 2004 and January 2009. Data from clinical-surgical records of tumor samples surgically removed, necropsy and cytological exams were used and sent for histopathology exams. During the study 210 tumors and about 27 different types of tumors were identified. Skin tumors (61.0\%) were the most frequent, followed by mammary gland tumors $(27.60 \%)$, reproductive system tumors $(11.90 \%)$ and bone system tumors. The mammary gland tumors were observed only in females, with high prevalence in bitches which were not spayed or spayed after two years old. It was concluded that the neoplasia prevalence increase was correlated to the higher longevity of dogs, and breed also contributed for the development of determined tumors due to high incidence of mastocitomas in Boxer and German Shepherd breeds. The $100 \%$ incidence of mammary gland neoplasia in females confirmed the higher predisposition for mammary gland neoplasia in females.
\end{abstract}

Keywords: dog, neoplasia, histopathology, Mozambique

Recebido em 19 de agosto de 2011

Aceito em 26 de novembro de 2012

E-mail: ivansantos7@hotmail.com 


\section{INTRODUÇÃO}

A oncologia é considerada uma área de grande relevância na medicina veterinária, e estima-se que as neoplasias constituam importante causa de óbito em animais de companhia (Souza et al., 2006). Estudos revelaram que $45 \%$ dos cães com 10 anos de idade ou mais chegam a óbito devido a complicações das neoplasias (Whithrow e MacEwen, 2007). Fatores como a nutrição com dietas equilibradas, vacinações que previnem precocemente doenças infectocontagiosas e avanços na medicina veterinária têm contribuído para a maior longevidade (De Nardi et al., 2002), a qual é apontada como principal razão para a crescente incidência das afecções neoplásicas nos cães (De Nardi et al., 2002; Rossetto et al., 2009).

A localização das diferentes neoplasias, em cães, varia conforme a idade, o sexo e a raça (De Nardi et al., 2002). Muitas neoplasias afetam com mais frequência animais de determinada idade, raça e sexo, sendo que essas informações auxiliam no diagnóstico delas (Gilson e Page, 2008). A pele é a principal localização das neoplasias nos animais domésticos, especialmente nos cães, representando $67,6 \%$ do total de neoplasias, seguindo-se as de glândula mamária, $15,1 \%$, e $17,3 \%$ encontram-se distribuídas pelos outros sistemas e órgãos (De Nardi et al., 2002; Souza et al., 2006). Withrow e MacEwen (2007) descreveram que esse tipo de afecção é doença que afeta animais idosos, mas, por outro lado, Sturion et al. (1997) diagnosticaram osteocondroma em um cão Fila Brasileiro de dois meses de idade.

No que se refere à raça, Gilson e Page (2008) constataram que os mastocitomas envolvem principalmente os cães braquicefálicos e que os tumores ósseos são mais frequentes nas raças grandes e gigantes. Em relação ao sexo, Maria et al. (1998) observaram maior prevalência de neoplasias em fêmeas da espécie canina, aproximadamente $71 \%$, quando comparadas aos machos.

As neoplasias mamárias representam, aproximadamente, $52 \%$ de todas as neoplasias da cadela, sendo que $50 \%$ delas ocorrem na forma maligna (Carvalho, 2006). A ovarios-salpingohisterectomia em cadelas jovens tende a reduzir a incidência delas (Queiroga e Lopes, 2002), e quando essa cirurgia é realizada antes do primeiro ciclo estral, o risco de desenvolver neoplasia mamária é de $0,5 \%$, de $8 \%$ quando realizada após o primeiro ciclo estral e de $26 \%$ quando o procedimento é realizado posteriormente a dois ciclos estrais (Morrison, 1998; Zuccari et al., 2001). As cadelas submetidas ao procedimento após os dois anos e seis meses de idade não são beneficiadas pelo efeito profilático dele (Morrison, 1998; Zuccari et al., 2001; Green et al., 2009).

Zuccari et al. (2001) citaram que, em pesquisas realizadas na Califórnia (EUA), foi observado que as fêmeas da espécie canina não esterilizada cirurgicamente apresentaram incidência de tumores mamários quatro a sete vezes maior quando comparadas às fêmeas submetidas à ovariossalpingo-histerectomia. Conforme Morrison (1998) e Withrow e Macwen (2007), as raças com maior incidência de neoplasias mamárias foram os Poodles, English Spaniel, Brittany Spaniel, Boxer, English Setter, Pionter, Fox Terrier, Boston Terrier e Cocker Spaniel, ao contrário das raças Grey Hound, Beagle e Chihuahua, que apresentaram menor risco.

Os mastocitomas são as neoplasias dos mastócitos, os quais têm origem na medula óssea e no tecido conjuntivo. Podem se localizar em qualquer tecido, mas são mais frequentes na pele, representando de $7,0 \%$ a $21,0 \%$ de todos os tumores de pele e $11,0 \%$ a $27,0 \%$ das neoplasias malignas em cães (Fox, 1998). Segundo o mesmo autor, as raças mais afetadas foram Boxers, Bulldog, Basset Hound, Weimaraner, Boston Terrier, Labrador Retriever, Beagle, Pointer e Scottish Terrier.

O hemangiossarcoma (HSA) é uma neoplasia maligna de origem endotelial vascular, que pode estar localizado no baço, fígado, coração, pele, pulmões, rins, músculos, ossos, bexiga urinária e peritônio (MacEwen, 2007). Acomete principalmente cães com idade variando entre oito e 13 anos e ocorre, majoritariamente, em raças de grande porte, como o Pastor Alemão, Labrador Retriever, Golden Retriever e Italian Greyhound (Schulteiss, 2004). MacEwen (2001) e Schultheiss (2004) citaram haver incidência aparentemente maior em machos, quando essa neoplasia está relacionada ao sexo, enquanto Prymak et al. (1985) não encontraram diferença 
significativa em sua pesquisa, embora tenham relatado maior incidência em fêmeas castradas quando comparadas com as fêmeas intactas.

Em razão da escassa publicação de relatos de dados de neoplasias em cães, em Moçambique, e do elevado número de cães acometidos por neoplasias, sendo necessário, portanto, um aprofundamento no estudo da oncologia veterinária, o presente trabalho tem como objetivo descrever os resultados do estudo retrospectivo da prevalência dos casos de neoplasias em 210 cães, atendidos no Hospital Veterinário Escola da Universidade Eduardo Mondlane, Moçambique, entre o período de janeiro de 2004 e janeiro de 2009. Por outro lado, divulgar a correlação de idade, sexo e raça e sua prevalência, a fim de que os resultados possam ser utilizados na comparação com os publicados na literatura internacional, ao se fornecerem dados de casuística de neoplasias e sua variação com as raças, o sexo e a idade.

\section{MATERIAL E MÉTODOS}

Foram utilizados dados das fichas clínicocirúrgicas do $\mathrm{HV}$, referentes às amostras de neoplasias removidas cirurgicamente, achados de exames necroscópicos e citológicos, do período de janeiro de 2004 a janeiro de 2009 , os quais, posteriormente, foram enviados para o diagnóstico histopatológico para o Laboratório de Anatomia Patológica da Universidade Eduardo Mondlane, Moçambique, para o respectivo diagnóstico histopatológico, estabelecendo-se, assim, o diagnóstico definitivo. Nos pacientes tratados cirurgicamente, procedeuse às exéreses das neoplasias com amplas margens de segurança, respeitando-se os princípios de cirurgia oncológica.

Os dados recolhidos referiram-se à informação sobre a idade, o sexo, a raça, a localização da neoplasia e o resultado do diagnóstico histopatológico. Para os casos de neoplasias mamárias nas cadelas, recolheu-se informação se as cadelas eram inteiras ou castradas, e para os casos das cadelas submetidas à ovariossalpingohisterectomia, registrou-se a idade em que foram submetidas ao procedimento. Os animais foram distribuídos em três classes, de acordo com a idade, em: cães jovens com idade entre zero e três anos, cães adultos com idade entre três e oito anos e cães idosos com idade maior que oito anos. Os dados foram tabulados em uma planilha do Excel, sendo efetuada a análise estatística descritiva. $\mathrm{O}$ estudo foi realizado de acordo com os princípios éticos do Colégio Brasileiro de Experimentação Animal e aprovado pela Comissão de Ética, com protocolo número 200/2011 - CEUA.

\section{RESULTADOS E DISCUSSÃO}

Conforme os objetivos do trabalho, nas tabelas e figuras abaixo estão presentes os dados estatísticos dos pacientes com neoplasia atendidos no $\mathrm{HV}$ da Universidade Eduardo Mondlane, Moçambique, entre janeiro de 2004 e janeiro de 2009. Na Tab. 1, demonstra-se a predominância dos diferentes tipos de neoplasias numa população de 210 cães. Observou-se que na mesma população foram diagnosticadas 210 neoplasias, sendo as de maior incidência as de pele, $61,0 \%$, seguidas das neoplasias de glândula mamária, 27,60\%, do sistema reprodutor, $11,90 \%$, e do sistema musculoesquelético, 11,0\%. Essa incidência foi semelhante com o citado por De Nardi et al. (2002), Souza et al. (2006) e Vail e Withrow (2007). Por outro lado, o hemangiossarcoma foi a única neoplasia dos vasos sanguíneos, representando 2,90\% de todas as neoplasias diagnosticadas durante o período de estudo.

As 210 neoplasias diagnosticadas durante o período de estudo foram o número de diagnósticos histopatológicos definitivos e registrados, podendo haver mais neoplasias não diagnosticadas, as quais foram, portanto, excluídas do estudo. Observaram-se 27 tipos diferentes de neoplasias, entre as quais aquelas que mais se destacaram foram o adenocarcinoma $(18,10 \%)$ e o adenoma de mama $(7,60 \%)$, o mastocitoma grau II $(8,10 \%)$, o osteossarcoma $(4,80 \%)$ e o tumor venéreo transmissível $(5,70 \%)$.

A incidência das neoplasias relacionadas com a idade está ilustrada na Fig. 1, demonstrando a ocorrência das neoplasias em cães com idade entre um e 15 anos. A maior predisposição ao desenvolvimento de neoplasias foi observada nos animais adultos e idosos, com idade variando entre três e 10 anos. 
Tabela 1. Porcentagem de neoplasias em cães atendidos no Hospital Veterinário da Universidade Eduardo Mondlane, Moçambique, de janeiro de 2004 a janeiro de $2009(\mathrm{n}=210)$

\begin{tabular}{|c|c|c|}
\hline Classificação histopatológica & Número de tumores & Porcentagem \\
\hline Adenocarcinoma de glândula sudorípara & 1 & 0,50 \\
\hline Adenocarcinoma de intestino delgado & 1 & 0,50 \\
\hline Adenocarcinoma de mama & 38 & 18,10 \\
\hline Adenocarcinoma de próstata & 2 & 1,0 \\
\hline Adenoma de glândula da terceira pálpebra & 1 & 0,50 \\
\hline Adenoma de glândula meibomiana & 2 & 1,0 \\
\hline Adenoma de mama & 16 & 7,60 \\
\hline Adenoma de glândula perianal (glândula hepatoide) & 5 & 2,40 \\
\hline Ameloblastoma acantomatoso canino & 1 & 0,50 \\
\hline Carcinossarcoma (tumor misto maligno de mama) & 4 & 1,90 \\
\hline Carcinoma das células escamosas & 8 & 3,80 \\
\hline Carcinoma de célula basal & 8 & 3,80 \\
\hline Carcinoma de epitélio de vesícula biliar & 4 & 1,90 \\
\hline Carcinoma endometrial & 3 & 1,40 \\
\hline Carcinoma hepatocelular & 7 & 3,30 \\
\hline Carcinoma sebáceo & 2 & 1,0 \\
\hline Condrossarcoma & 4 & 1,90 \\
\hline Fibroma & 3 & 1,40 \\
\hline Fibroma periférico odontogênico & 3 & 1,40 \\
\hline Fibrossarcoma cutâneo & 5 & 2,40 \\
\hline Fibrossarcoma esquelético & 4 & 1,90 \\
\hline Hemangiossarcoma & 6 & 2,90 \\
\hline Histiocitoma cutâneo & 8 & 3,80 \\
\hline Leiomioma & 1 & 0,50 \\
\hline Linfoma cutâneo & 4 & 1,90 \\
\hline Lipoma & 3 & 1,40 \\
\hline Lipossarcoma & 2 & 1,0 \\
\hline Mastocitoma grau II & 17 & 8,10 \\
\hline Melanoma & 6 & 2,90 \\
\hline Osteoma & 2 & 1,0 \\
\hline Osteossarcoma & 10 & 4,80 \\
\hline Papiloma cutâneo & 2 & 1,0 \\
\hline Rabdomioma & 3 & 1,40 \\
\hline Seminoma teratoma & 3 & 1,40 \\
\hline Tricoblastoma & 1 & 0,50 \\
\hline Tricoepitelioma & 4 & 1,90 \\
\hline Tumor de células de Sertoli benigno & 4 & 1,90 \\
\hline Tumor venéreo transmissível & 12 & 5,70 \\
\hline
\end{tabular}


A elevada incidência de neoplasias, atribuída ao aumento da longevidade dos cães, referida por Maria et al. (1998), De Nardi et al. (2002) e Withrow e MacEwen (2007), também foi observada neste estudo, em que a maior representação das neoplasias ocorreu em cães com 10 anos de idade. Segundo De Nardi et al. (2002), as neoplasias raramente surgem em cães com menos de um ano de idade, fato constatado no estudo. A idade pode ser um fator predisponente às afecções oncológicas conforme afirmaram Withrow e MacEwen (2007), pois não se diagnosticou nenhuma neoplasia em animais com menos de um ano de idade, sendo esses casos extremamente raros (Sturion et al., 1997).

A predisposição das raças em relação às neoplasias está representada na Tab. 2, observando-se maior incidência nos cães sem raça definida $(16,70 \%)$, seguidos dos cães das raças Pastor Alemão $(13,81 \%)$ e Maltesa $(11,0 \%)$.

Tabela 2. Porcentagem de neoplasias em cães diagnosticadas no Hospital Veterinário da Universidade Eduardo Mondlane, Moçambique, de janeiro de 2004 a janeiro de 2009, conforme a raça $(n=210)$

\begin{tabular}{lcc}
\hline Raça acometida & Número de animais & Porcentagem \\
\hline Boer Bull & 10 & 4,80 \\
Border Collie & 3 & 1,40 \\
Bouvier Bernois & 3 & 1,40 \\
Boxer & 19 & 9,10 \\
Bull Mastiff & 3 & 1,40 \\
Bull Terrier & 12 & 5,72 \\
Chow Chow & 3 & 1,40 \\
Cocker Spaniel & 3 & 1,40 \\
Dauchshund & 3 & 1,40 \\
Doberman & 3 & 1,40 \\
Fox Terrier & 3 & 1,40 \\
Great Dane & 3 & 1,40 \\
Husky Siberiano & 3 & 1,40 \\
Jack Russel & 3 & 1,40 \\
Labrador & 10 & 4,80 \\
Leão da Rodésia & 14 & 6,70 \\
Maltês & 23 & 11,0 \\
Pastor Alemão & 29 & 13,81 \\
Pastor Belga & 3 & 1,40 \\
Pinscher & 3 & 1,40 \\
Pit Bull & 3 & 1,40 \\
Rottweiller & 16 & 7,62 \\
Cães sem raça definida & 35 & 16,70 \\
\hline
\end{tabular}

A Fig. 2 ilustra a predominância das doenças neoplásicas conforme o sexo, sendo que, na população de 210 cães, as fêmeas foram as mais acometidas, 121 casos, correspondendo a $58 \%$ da casuística, versus 89 casos nos machos, representando $42 \%$. A alta prevalência de tumores nas fêmeas em relação aos machos esteve correlacionada com o elevado número de neoplasias de glândula mamária, 58 casos contra os 63 casos de neoplasias em outros órgãos.

Conforme mostra a Fig. 3, as neoplasias de glândula mamária representaram $27,60 \%$ de todas as neoplasias na fêmea canina, sendo que a maior incidência registrada foi do adenocarcinoma de mama, $18,10 \%$, seguido do 
adenoma de mama, $7,60 \%$ e do carcinossarcoma ou tumor misto maligno de mama, $1,90 \%$. Nesse contexto, os proprietários devem ser orientados sobre a importância da esterilização precoce como medida profilática na oncogênese mamária (Morrison, 1998; Zuccari et al., 2001).

O maior número de fêmeas em relação aos machos e o índice de malignidade $(20,0 \%)$ foi inferior ao citado por De Nardi et al. (2002) (acima de 50\%).

As neoplasias de glândula mamária foram identificadas somente em cadelas e contribuiu para a maior frequência em fêmeas (De Nardi et al., 2002), sendo o tipo neoplásico mais diagnosticado e mais comum em cadelas entre cinco e 12 anos de idade (Fonseca e Daleck, 2000; Green et al., 2009). A prevalência das neoplasias de mama em cadelas não castradas foi de $64,0 \%$ e nas castradas foi de $36,0 \%$. A maior prevalência foi observada em cadelas submetidas à ovariossalpingo-histerectomia (OSH) após os dois anos de idade, conforme mostra a Tab. 3, sendo o adenocarcinoma de mama com maior prevalência, $42,5 \%$. As neoplasias de glândula mamária predominantes em fêmeas não submetidas à OSH foram constatadas por Green et al. (2009).

Tabela 3. Porcentagem de neoplasias de glândula mamária em cadelas submetidas à ovarios-salpingohisterectomia (OSH) antes e após os dois anos de idade, no Hospital Veterinário da Universidade Eduardo Mondlane, Moçambique, de janeiro de 2004 a janeiro de 2009 ( $\mathrm{n}=210)$

\begin{tabular}{lcc}
\multicolumn{1}{c}{ Tipo de neoplasia } & \multicolumn{2}{c}{ Ovariossalpingo-histerectomia (OSH) } \\
\cline { 2 - 3 } & $\begin{array}{c}\text { OSH antes dos dois anos e } \\
\text { seis meses de idade } \\
(\%)\end{array}$ & $\begin{array}{c}\text { OSH após os dois anos e seis } \\
\text { meses de idade } \\
(\%)\end{array}$ \\
\hline Adenocarcinoma de mama & 10,0 & 42,5 \\
Adenoma mamário & 0 & 9,5 \\
Carcinossarcoma & 5,0 & 33,0 \\
\hline
\end{tabular}

As neoplasias de glândula mamária ocorreram com maior frequência na raça Maltesa $(21,0 \%)$, seguida da raça Pastor Alemão $(16,0 \%)$ e de cães sem raça definida $(12,0 \%)$. Queiroga e Lopes (2002) e Carvalho (2006) afirmaram não existir predisposição racial para o desenvolvimento das neoplasias mamárias; por sua vez, Daleck et al. (1998) e Green et al. (2009) se referiram ao fato de que as raças puras são mais susceptíveis ao desenvolvimento desse tipo de neoplasia, o que também foi observado no presente trabalho. Segundo Queiroga e Lopes (2002) e De Nardi et al. (2002), cadelas da raça Boxer apresentaram maior frequência de neoplasias mamárias e cadelas sem raça definida maior em relação ao Boxer, fato constatado, também, por Furian et al. (2007) e Green et al. (2009). Essa constatação pode estar associada à maior representatividade dos animais sem raça definida, na população em estudo.

O fato de as neoplasias de glândula mamária serem observadas apenas em cadelas confirma a predisposição sexual em fêmeas para o desenvolvimento delas, devido à presença de hormônios sexuais femininos (Misdrop, 2002). Contudo, Carvalho (2006) ressaltou que as neoplasias mamárias também podem ocorrer em machos, ainda que em baixa frequência, menor que $1,0 \%$. A variação porcentual das frequências pode ser explicada pelo diferente tamanho da amostra nos diferentes estudos desenvolvidos por Green et al. (2009), como também pela provável variação na exposição aos diferentes agentes carcinogênicos.

O mastocitoma grau II $(8,10 \%)$, o histiocitoma cutâneo $(3,80 \%)$, o carcinoma das células escamosas $(3,80 \%)$ e o melanoma $(2,90 \%)$ foram as neoplasias cutâneas mais diagnosticadas no estudo, semelhante ao descrito por Bellei et al. (2006). Através dos dados, foi possível correlacionar a alta incidência de mastocitomas grau II afetando os cães sem raça definida $(17,0 \%)$, seguidos dos cães das raças Boxer (14,0\%), Pastor Alemão (13,0\%) e Leão da Rodésia (11,0\%) (Fig. 4).

Dentro do grupo dos animais de raça, o Boxer apresentou a maior frequência de neoplasias 
cutâneas, seguido do Pastor Alemão, semelhante ao citado por Rossetto et al. (2009). Outras raças, descritas pelos mesmos autores, com elevada frequência de neoplasias cutâneas foram $\mathrm{o}$ Poodle Miniatura e o Fila Brasileiro, sendo que essas raças não são reportadas por serem de baixo porcentual de existência na região de estudo.

Stannard e Rulley (2002) e Goldschmidt e Hendrick (2002) relataram que não existe predisposição por sexo para as neoplasias cutâneas, diferentemente dos resultados de Souza et al. (2006). Paralelamente aos resultados de Souza et al. (2006), no presente estudo as neoplasias cutâneas desenvolveram-se mais em machos $(56,50 \%)$ comparativamente às fêmeas (43,5,0\%). Carvalho (2006) e Sanja et al. (2005) referiram que o mastocitoma e o melanoma são mais frequentes em machos, o que também foi observado no estudo, sendo que as frequências do mastocitoma foram de $32,0 \%$ nos machos e de $11,0 \%$ nas fêmeas. Por outro lado, em relação ao melanoma, a incidência foi de 19,0\% nos machos e de $7,0 \%$ nas fêmeas. Souza et al. (2006), em um estudo retrospectivo de 761 tumores cutâneos em cães, em Santa Maria, Brasil, reportaram o mastocitoma como sendo a neoplasia mais prevalente, semelhante ao resultado deste estudo.

No estudo, o mastocitoma ocorreu em animais entre três e oito anos de idade e maiores que oito anos de idade. Resultado semelhante foi observado num estudo retrospectivo de mastocitomas em cães, realizado por Furlani et al. (2008), os quais citaram que o mastocitoma afetou em maior porcentagem animais com idade entre seis e nove anos.

O tumor venéreo transmissível (TVT) foi a neoplasia do sistema reprodutor com maior frequência $(5,70 \%)$, e sua prevalência em relação ao sexo, nos 12 animais da população em estudo, foi de $50,0 \%$ para ambos os sexos. No que concerne à idade, os pacientes com idade entre três e oito anos foram os mais acometidos, $56,0 \%$. Os cães sem raça definida foram os mais afetados $(33,30 \%)$, seguidos do Pastor Alemão (25,0\%) (Fig. 5), fato ressaltado por Sousa et al. (2000) e Florentino et al. (2006), os quais reportaram que os cães sem raça definida fazem parte do grupo com maior risco de desenvolver o TVT, bem como os que habitam áreas de alta densidade populacional e com elevada prevalência de animais abandonados. Nos 12 pacientes acometidos por TVT, constatou-se que 11 tinham acesso a ruas e contato com animais não domiciliados, semelhante ao descrito por De Nardi et al. (2002).

O osteossarcoma foi a neoplasia mais prevalente das neoplasias musculoesqueléticas, 4,80\%, ocorrendo com igual frequência em cães machos e fêmeas, $50 \%$, e com maior porcentagem em pacientes com idade entre três e oito anos, $50 \%$. Silveira (2008) reportou que as neoplasias ósseas são mais frequentes em machos, podendo a proporção macho-fêmea variar de 1,2:1 a 1,5:1, diferentemente dos resultados deste trabalho, em que se observou uma proporção macho-fêmea de 1:1. Quanto à raça, as mais acometidas foram as Bull Terrier e Rottweiller, 30,0\% para ambas, seguidas da raça Leão da Rodésia, 30,0\%, e cães sem raça definida, 10,0\%. Silveira et al. (2008) referiram-se ao osteossarcoma como a neoplasia óssea primária mais frequente em cães, podendo representar até $90,0 \%$ das neoplasias ósseas. No presente estudo, o osteossarcoma representou $50,0 \%$ das neoplasias ósseas diagnosticadas.

Em relação às neoplasias dos vasos sanguíneos, o hemangiossarcoma (HSA) foi a única diagnosticada durante o período de estudo, apresentando a mesma porcentagem em machos e fêmeas, $50 \%$, contrariamente ao que foi citado por Prymak et al. (1985), MacEwen (2001) e Schultheiss (2004). Os cães com idade entre três e oito anos e com mais de oito anos foram acometidos em $67,0 \%$ e $33,0 \%$, respectivamente. Segundo Stannard e Rulley (2002) e Schultheiss (2004), o HSA foi observado majoritariamente em cães com mais de oito anos de idade, com igual distribuição entre machos e fêmeas. A ocorrência do HSA variou de acordo com a localização anatômica, sendo 50,0\% cutâneos e $50,0 \%$ viscerais, distribuídos no baço $(33,0 \%)$ e no fígado $(17,0 \%)$. A raça Pastor Alemão foi a mais diagnosticada com o HSA, 33,3\%, semelhante ao descrito por Schultheiss (2004), seguida das raças Bull Terrier, Boer Bull, Pincher e de cães sem raça definida, $16,67 \%$ para cada raça (Fig. 6). 


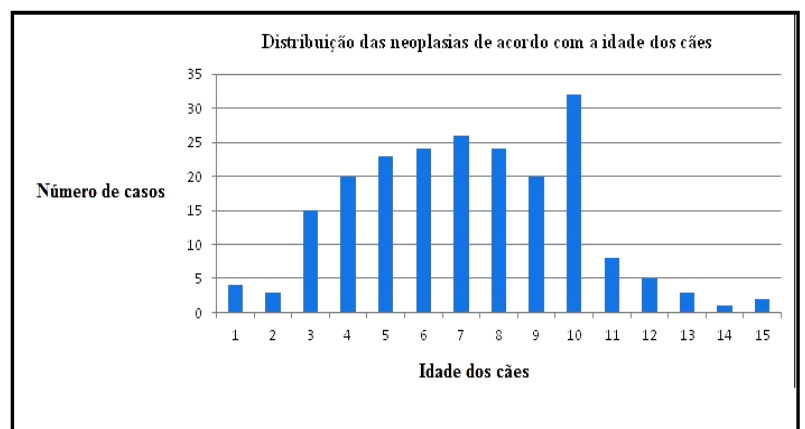

Figura 1. Distribuição do número de neoplasias em cães atendidos no Hospital Veterinário da Universidade Eduardo Mondlane, Moçambique, de janeiro de 2004 a janeiro de 2009, conforme a idade em anos $(n=210)$.

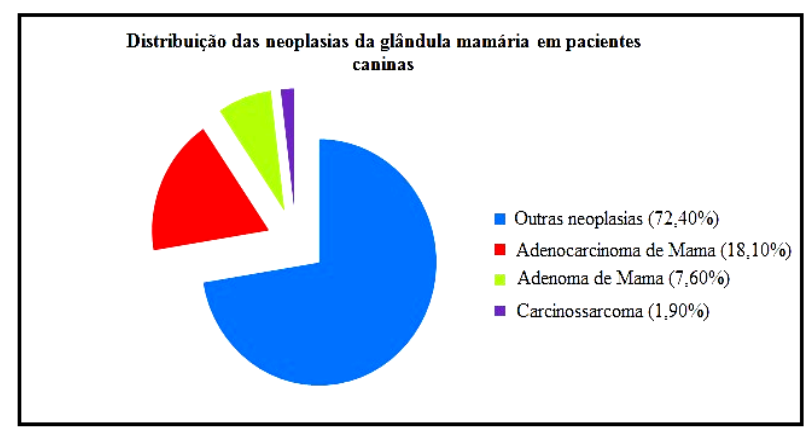

Figura 3. Distribuição das neoplasias de glândula mamária em pacientes caninas, diagnosticadas no Hospital Veterinário - Universidade Eduardo Mondlane, Moçambique, de janeiro de 2004 a janeiro de 2009 $(\mathrm{n}=210)$.

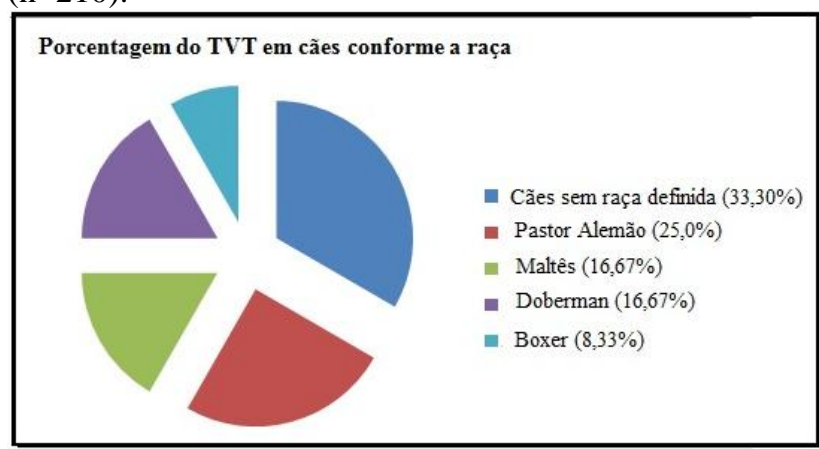

Figura 5. Prevalência do tumor venéreo transmissível (TVT) em cães, atendidos no Hospital Veterinário da Universidade Eduardo Mondlane, Moçambique, de janeiro de 2004 a janeiro de 2009, conforme a raça.

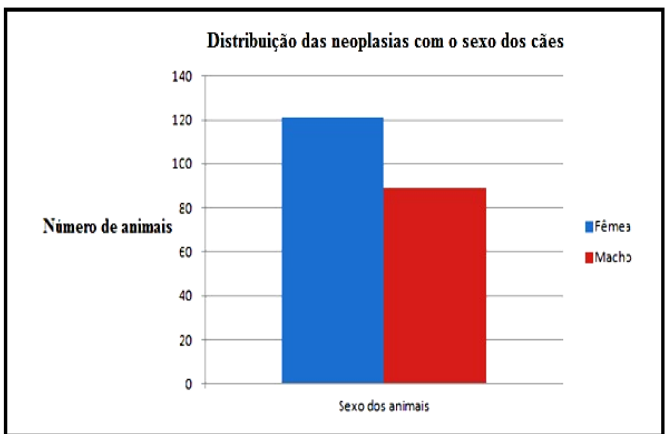

Figura 2. Distribuição das neoplasias caninas diagnosticadas no Hospital Veterinário da Universidade Eduardo Mondlane, Moçambique, de janeiro de 2004 a janeiro de 2009, conforme o sexo $(n=210)$.

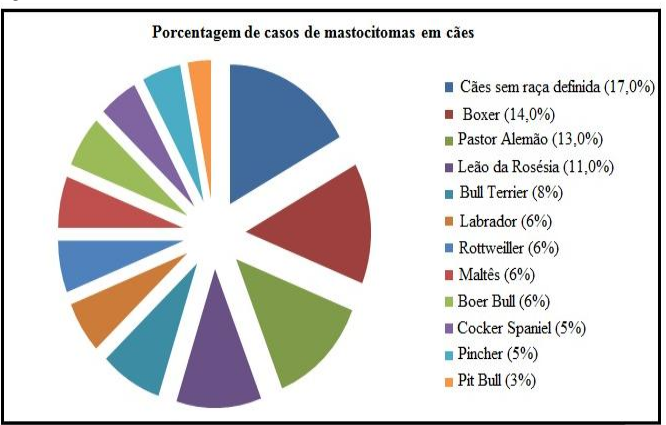

Figura 4. Porcentagem dos mastocitomas grau II em cães, atendidos no Hospital Veterinário da Universidade Eduardo Mondlane, Moçambique, de janeiro de 2004 a janeiro de 2009, conforme a raça.

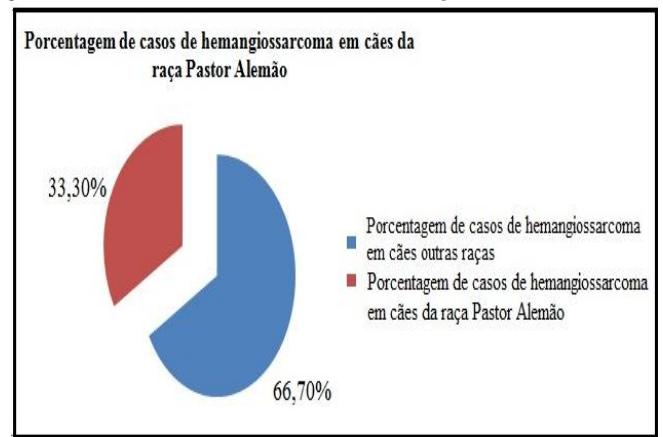

Figura 6. Porcentagem de hemangiossarcoma em cães da raça Pastor Alemão, atendidos no Hospital Veterinário da Universidade Eduardo Mondlane, Moçambique, de janeiro de 2004 a janeiro de 2009, comparada com a frequência em outras raças. 


\section{CONCLUSÃO}

Conclui-se que o aumento da prevalência das neoplasias está correlacionado com a maior longevidade dos cães, sendo que as neoplasias foram mais frequentes nos animais mais velhos, com três a 10 anos de idade. A raça, também, predispõe ao desenvolvimento de determinados tumores, haja vista a alta incidência de mastocitomas em cães das raças Boxer e Pastor Alemão. A incidência de $100 \%$ das neoplasias de glândula mamária em fêmeas, sendo 20,0\% malignas, confirma a maior predisposição das fêmeas no desenvolvimento desse tipo de neoplasia.

\section{REFERÊNCIAS}

BELLEI, M.H.M.; NEVES, D.S.; GAVA, A. et al. Prevalência de neoplasias cutâneas diagnosticadas em caninos no estado de Santa Catarina, Brasil, no período entre 1998 a 2002. Rev. Cienc. Agrovet., v.5, p.73-79, 2006.

CARVALHO, T.B. Neoplasia mamária em cadelas: caracterização histopatológica e expressão de proteínas de estresse (HSP 72). Dissertação (Mestrado em Medicina Veterinária) - Universidade Federal de Viçosa, Minas Gerais, 2006. Online. Disponívelem:http://www.tede.ufv.br/tedesimplif icado/tde_busca/arquivo.php?codArquivo $=449$. Acessado em: 27 jan. 2010.

DE NARDI, A.B.; RODASKI, S.; SOUSA, R.S. et al. Prevalência de neoplasias e modalidades de tratamento em cães, atendidos no hospital veterinário da Universidade Federal do Paraná. Arch. Vet. Sci., v.7, p.15-26, 2002.

FLORENTINO, K.C. Tumor venéreo transmissível cutâneo canino - relato de caso. Rev. Cient. Med. Vet. Zootec. Graça/FAMED, n.7, 2006.

FONSECA, C.S., DALECK, C.R. Neoplasias mamárias em cadelas: influência hormonal e efeitos da ovário-histerectomia como terapia adjuvante. Cienc. Rural, v.30, p.731-735, 2000.

FOX, L.E. Mast cell tumors. In: MORRISON, W.B. Cancer in Dogs and Cats: Medical and Surgical Management. Baltimore: Williams \& Wilkins, 1998. p.477-486.
FURIAN, J.M.; SANDEI, C.F.; ROCHA, E.N. et al. Estudo retrospectivo dos tumores mamários em caninos e felinos atendidos no Hospital Veterinário da FAMED entre 2003 e 2007. Rev. Cient. Med. Vet. Zootec. Graça/FAMED, n.8, p.231-233, 2007.

FURLANI, J.M.; DALECK, C.R; VICENTI, F.M. et al. Mastocitoma canino: Estudo retrospectivo. Cienc. Anim. Bras., v.9, p.242250, 2008.

GILSON, S.D.; PAGE, R.L. Princípios de Oncologia. In: BIRCHARD, S.J.; SHERDING, R. G. Manual Saunders: Clínica de Pequenos Animais. 3.ed. São Paulo: Roca, 2008. p.209217.

GOLDSCHMIDT, M.H.; HENDRICK, M.J. Hemangiossarma. In: MEUTEN, D.J. Tumors in domestic animals. 4.ed. Iowa: Iowa State, 2002. p.99-101.

GREEN, K.T.; FRANCIOSI, A.; BECKERT, M. et al. Incidência de neoplasia mamária em fêmeas caninas atendidas no Hospital Veterinário da Universidade Federal do Paraná - In: ENCONTRO INTERNACIONAL DE PRODUÇÃO CIENTÍFICA CESUMAR, VI, 2009, Curitiba. Anais... Curitiba: [s.n.] 2009. p.32. (Resumo).

MACEWEN, E.G. Miscellaneous Tumors. In: WITHROW, S.J.; MACEWEN, E.G. Small animal clinical oncology. Philadelphia: W. B. Saunders, Company, 2007. p.639-646.

MARIA, P.P.; SOBRAL, R.A.; DALECK, C.R. Casuística de cães portadores de neoplasias atendidos no Hospital Veterinário da Unesp/Jaboticabal durante o período de 01/01/95 a 01/05/97. In: CONGRESSO BRASILEIRO DE CIRURGIA E ANESTESIOLOGIA, IX, 1998, Belo Horizonte. Anais... Belo Horizonte: [s.n.]. Jornal Brasileiro de Ciência Animal - JBCA, 2010. p. 120-122.

MISDROP, W. Tumors of the mammary gland. In: MEUTEN D.J. Tumors in domestic animals. 4 ed. Iowa: State Press, 2002.Cap.18, p.575-577.

MORRISON, W.B. Cancer in Dogs and Cats: Medical and Surgical Management. Baltimore: Williams \& Wilkins, 1998. p.591-598. 
PRYMAK, C.; MCKEE, L.J.; GOLDSCHMIDT, M.H. et al. Epidemiologic, clinical, pathologic, and prognostic characteristics of splenic hemangiosarcoma and splenic hematoma in dogs: 217 cases. J. Am. Vet. Med. Assoc.. v.193, p.706-712, 1988.

QUEIROGA, F.; LOPES, C. Tumores mamários caninos - Novas perspectivas. In: CONGRESSO DE CIÊNCIAS VETERINÁRIAS. SPCV. 2002. Oeiras. Anais... Lisboa: [s.n.] 2002. p.183-190. (Resumo).

ROSSETTO, V.V.; MORENO, K.; GROTTI, C.B. et al. Frequência de neoplasmas diagnosticados por exame citológico: estudo retrospectivo em um hospital-escola. Semina: Cienc. Agrárias. v.30, p.189-200, 2009.

SANJA, A.K. Retrospective analysis of canine mesenchimal tumors of skin and soft tissues. Acta Vet., v.55, p.521-529, 2005.

SCHULTEISS, P.C. A retrospective study of visceral and nonvisceral hemangiosarcoma and hemangiomas in domestic animals. J. Vet. Diagnostic Investigat., n.16, p. 522-56, 2004.

SILVEIRA, P.R.; COELHO, H.E.; QUEIROZ, F.F. et al. Estudo retrospectivo de osteossarcoma apendicular em cães. Cienc. Anim. Bras., v.9, p.487-495, 2008.

SOUSA, J.; SAITO, V.; NARDI, A.B. et al. Características e incidência do tumor venéreo transmissível (TVT) em cães e eficiência da quimioterapia e outros tratamentos. Arch. Vet. Sci., v.5, p.41-48, 2000.
SOUZA, T.M.; FIGHERA, R.A.; IRIGOYEN, L.F. et al. Estudo retrospectivo de 761 tumores cutâneos em cães. Cienc. Rural., v.36, p.555560, 2006.

STANNARD, A.; RULLEY, L.T. Tumors of the skin and soft tissues. In: MOULTON, J.E.(ED). Tumors in domestic animals. 3 ed. Los Angeles:University of California Press, 2002. p.35-36.

STURION, D.J.; SANTOS, P.G.; SANTOS, R.V. et al. Osteocrondoma em cão Fila Brasileiro. In: CONGRESSO BRASILEIRO DE CLÍNICOS VETERINÁRIOS DE PEQUENOS ANIMAIS, XIX, 1997, Curitiba. Anais... Curirtiba: Associação Nacional de Clínicos Veterinários de Pequenos Animais - Paraná, 1997. p. 48. (Resumos).

VAIL, D.M.; WITHROW, S.J. Tumors of the skin and subcutaneous tissues. In: WITHROW, S.J.; MACEWEN, E.G. Small Anim. Clin. Oncol. Philadelphia: W.B. Saunders, 2007. p.167-191.

WITHROW, S.J.; MACEWEN, E.G. Cancer. In: WITHROW, S.J.; MACEWEN, E.G. (Ed.). Small animal clinical oncology. 4.ed. Philadelphia: W. B. Saunders Company, 2007. p.15-17.

ZUCCARI, D.C.; SANTANA, A.E.; ROCHA, N.S. Fisiopatologia da neoplasia mamária em cadelas - revisão. Clín. Vet., n.32, p.50-54, 2001. 